\title{
Peripheral Zone of the Prostatic Parenchyma
}

National Cancer Institute

\section{Source}

National Cancer Institute. Peripheral Zone of the Prostatic Parenchyma. NCI Thesaurus.

Code C33308.

Prostatic parenchyma that occupies the posterior and lateral aspects of the prostate gland. The glandular architecture consists of small, round acini amid loosely woven, randomly oriented stroma. The peripheral zone contains large, so-called main glands, whose ducts run posteriorly to open into the urethra. Approximately $70 \%$ of the prostate gland lies in the peripheral zone. 